\title{
The Teaching of Inquiry-based Science in Elementary Classrooms: A Bi-national Comparative Reflection of US and Lithuanian Practices
}

\author{
Bobbi Hansen ${ }^{1} \&$ Sandy Buczynski ${ }^{1}$ \\ ${ }^{1}$ School of Leadership and Education Sciences, University of San Diego, San Diego, California \\ Correspondence: Bobbi Hansen, School of Leadership and Education Sciences, University of San Diego, San Diego, \\ California, 92110 Tel: 760-533-1183. E-mail: chansen@sandiego.edu Canada
}

Received: June 9, 2013

Accepted: July 1, 2013

Online Published: July 5, 2013

doi:10.5430/ijhe.v2n3p41

URL: http://dx.doi.org/10.5430/ijhe.v2n3p41

\begin{abstract}
This paper offers a comparative reflection on how two nations, the U.S. and Lithuania, are implementing inquiry-based science in elementary classrooms. The qualitative study explored how fourth grade teachers in Southern California and in Lithuania employed effective inquiry-based strategies in their classrooms. A teacher's use of questioning strategies to guide critical thinking and the role of inquiry-based pedagogy plays in promoting student engagement were commonalities in both countries. "Exercise moments", resource conservation, and "voyeuristic investigations" were noted in Lithuanian inquiry practices while pacing guides and standards coverage were prevalent issues in US inquiry practices.
\end{abstract}

Keywords: Inquiry-based science, Questioning strategies, TIMSS, $21^{\text {st }}$ century skills

\section{Introduction}

\subsection{Introduction}

How do we probe to determine the level of a learner's knowledge? We ask questions. What is the basis of high stakes assessment instruments? --multiple choice and short answer questions. Given the importance placed on being able to answer high stakes' questions, the powerful nature of questioning in the classroom is often overlooked (Crow \& Stanford, 2010). Yet, questioning as a means of providing an opportunity to develop new ideas and understandings is not a new concept. Socrates popularized the use of questioning in a unique teaching style meant to stimulate thought, analysis, and search of knowledge (Crockett, 2004). Today's science teachers are once again capturing the strength of questioning to engage students in active learning through the implementation of inquiry-based pedagogy. At the heart this inquiry approach is the ability to identify, ask, and answer scientific questions.

Indeed, interest in inquiry-based teaching has become is a worldwide phenomenon. In an international comparative study (Abd-El-Khalick et.al., 2004), defines stages of inquiry where approaches range from fairly straightforward and somewhat structured laboratory- activities, to a divergent approach for generating evidence-based answers to open-ended question. In the US, the National Research Council (1996) led the call for inquiry instruction to promote coherent understanding and improve science achievement. Researchers in many countries have responded to this call and found that students in inquiry-based group reached significantly higher levels of achievement than students experiencing traditional instruction (Wilson, Taylor, Kowalski, \& Carlson, 2010; Geier, Blumenfeld, Marx, Krajcik, Fishman, \&Soloway, 2012). Across the Atlantic, the European Commission released a report and concluded that pedagogical practices based on inquiry-based methods are more effective for the teaching and learning of science. And in Asia, a study by Chang and Mao (1999) in Taiwan suggested that students who received inquiry-based science instruction outperformed students in the control group and had more positive attitudes toward science.

\subsection{Importance of the Problem}

According to the National Science Education Standards, inquiry is "the way in which scientists study the natural world and propose explanations based on the evidence derived from their work. Scientific inquiry also refers to the activities through which students develop knowledge and understanding of scientific ideas, as well as an understanding of how scientists study the natural world" (p.23). Foundational to the understanding of inquiry, is an examination of the original works of John Dewey. Science has been taught too much as an accumulation of ready-made material with which students are to be made familiar, not enough as a method of thinking, and attitude of mind after the pattern of which mental habits are to be transformed (Dewey, 1964, p. 183, first published 1910). In an 
attempt to enhance science education, both the U.S. and Lithuania have instituted reform efforts that revolve around inquiry-based pedagogy. Even though in Lithuania, a student's primary education (grades 1-4) focuses on world discovery with 200 hours spent on natural sciences plus social and moral education, and grades $5 \& 6$ focus on the content of nature and man, teachers are becoming more and more proficient in taking an inquiry approach to this content. Similarly in the U.S. (specifically California), learners in primary grades 1-5 are introduced to science concepts via content standards in physical, life, and earth sciences that progress in rigor as students move through the elementary grades. However, in addition to this content laden curriculum, students are also introduced to inquiry in the processes of experimentation and investigation.

Inquiry pedagogy is significant for science educators because it is student-centered and allows time for metacognitive development (Inoue \& Author \#2, 2011). In an inquiry classroom the teacher presents an open-ended problem, and the learners explore solutions by defining a process, gathering data, analyzing the data and the process, and developing an evidence-supported claim or conclusion. In order to deliver an effective inquiry lesson, a set of general principles are generally followed: a) the lesson begins with a meaningful problem or question that is relevant to students' interests and everyday experiences; b) students are provided with opportunities to blend new knowledge with their prior knowledge; $\mathrm{c}$ ) teachers guide students to decide what answers are best by giving priority to evidence in responding to their questions; d) exchanges of different perspectives are promoted while encouraging students to formulate explanations from evidence; and e) learners are provided with opportunities to connect explanations to conceptual understanding (Inoue \& Author \#2, 2011).

In both the US and Lithuania, the current science curriculum and its learning environment are moving towards inquiry-based pedagogy. In both countries, teachers are engaging in professional development (PD) to strengthen their ability to implement this methodology. The purpose of this research is to reflect upon and make comparisons regarding how teachers in the US and in Lithuania, separated by geography and culture, are each responding to implementing an inquiry-based pedagogy. Specifically, we compared teacher questioning and student responses during inquiry-based science lessons in schools in southern California and in Lithuania.

\subsection{Relevant Scholarship}

According to Author \#2 and Author \#1 (2010), several waves of national science teaching reform have transpired over the last 40 years. Every one of these reform movements have emphasized that learning through inquiry is essential to learning science. Most educators credit Joseph Schwab with developing the concept of inquiry in 1965 as he was proposing science instruction that closely paralleled the work of real scientists (Wallace \& Kang, 2004). More recently, Linn, Davis, and Bell (2004) defined inquiry as the intentional process of diagnosing problems and critiquing experiments, as well as distinguishing alternatives, planning investigations, researching conjectures, searching for information, constructing models, debating with peers, and forming coherent arguments.

In the 1990's Lithuania, like other countries that were referred to as "Soviet satellites," emerged as an independent nation and retained much of their culture and educational heritage. Like all nations, they sought to pass on important aspects of cultural and national identity through schooling. "In the context of Lithuanian education today, the emphasis on rote learning over critical thinking skills - characteristic of education under the former socialist system-persists, making it more difficult for Lithuania to emulate the modern European model of education" (Juceviceniene, 2005, p. 14). However, Juceviceniene goes on to note that this situation this improving, as illustrated by the results of the International Studies in Mathematics and Natural Sciences (TIMSS, 1997) that show that Lithuanian students have made the greatest rates of improvement as compared to students from all other nations in the survey.

TIMSS was the most extensive and far-reaching cross-national comparative study ever attempted within education (Schmidt \& McKnight, 1995). Testing was conducted at the $4^{\text {th }}, 8^{\text {th }}$, and $12^{\text {th }}$ grade levels in the content areas of science and math. In the 2007 TIMSS results, the average science scores for all nations testing eight graders, put Singapore on top (567), Serbia on bottom (470) and the U.S.(520) and Lithuania (519) in the middle of the pack. By 2013, TIMSS results indicated that Lithuanian eight graders were significantly outscoring their U.S. counterparts (NCES publication number 2013-009). In addition, a report by Harvard University's Program on Education Policy and Governance found that students in Lithuania are improving at twice the rate as U.S. students (Hanushek, Peterson, \& Woessmann, 2012). These results serve as a wake up call to the US as there is a growing consensus that U.S. students study too many science topics, but not in enough depth; that science education is a mile long and an inch deep (It is imperative that all nations sufficiently educate their youth in science content as increasingly, and globally, students are growing up to make such personal choices as whether or not to vaccinate their children, eat genetically modified foods, or decide on how much energy to use. These important decisions require foundational 
science literacy. Additionally, discussion of the TIMSS achievement results has prompted US policy-makers, as well as those from other countries, to consider more carefully what it might mean to have a "world-class" science curriculum (Valverde \& Schmidt, 2000).

Why are other countries doing better in science than the U.S.? According to Butrymowicz (2011), while U.S. students are memorizing science facts in early grades, students in other countries are learning foundational concepts that make complicated processes understandable in later grades. Without knowledge of the fundamentals, students can only gain superficial knowledge of a subject. Butrymowicz also attributes U.S. students' lack of success in science to following procedural steps during experimentation rather than being challenged to explain scientific concepts behind the experiments and to engaging in "fun" activities, such as puzzles, games or stories, rather than creating a science content story line that focuses on the main idea of a lesson that makes clear connections to the "fun" activities. Refocusing the curriculum to an inquiry approach will help students learn the $21^{\text {st }}$ century skill of critical thinking to learn to critically analyze the pros and cons of science-based $21^{\text {st }}$ century problems.

Questions and questioning practices have driven instruction in education for many years. One of the trickiest aspects to the implementation of the inquiry process is in the way questions are used in the classroom. Around the world, the norm is for teachers to pose questions to check knowledge or understanding of concepts. It is the role of students to try to answer a teacher's question and, in most cases, to produce the answer that the teacher has in mind. In inquiry-based science, however, the way a teacher approaches the questioning process becomes a critical factor (Biddulph, Symington, \& Osborne, 1986; Keys, 1998; Roth \& Roychoudhury, 1993; Selley et al., 1992; Watts \& Alsop, 1995; Watts, Gould, \& Alsop, 1997). Therefore, there has been keen interest, internationally, in the effects of different teacher approaches to questioning on students' science learning. In Singapore, Chin (2004) has done much research on questioning and found that "students can be stretched mentally through sensitive teacher-led but not teacher-dominated discourse" (pp. 1343). In research in the Baltic nations in Europe, O'Loughlin (1992) found that mediation by teachers' questions can draw students' attention to the facts that generate cognitive conflict and to those that can generate a possible solution to the problem. From this point of view, the types of questions that are used during teachers' mediation are crucial to the cognitive processes that are employed by students. And in studies done in Australia, Murcia (2007) concludes that primary teachers' approaches to questioning in science should arise from students' own curiosity into a context. Following up on ways that teachers' questions can promote that student engagement and scientific curiosity, Chin and Kayalvizhi (2002) suggest the following:

1. Teach pupils about the nature and structure of investigations, the different types of investigations that can be carried out, and the kinds of investigable questions that lend themselves to practical investigations.

2. Guide pupils to transform their non-investigable questions to investigable ones through skillful teacher questioning and discussion.

3. Tap on pupils' prior knowledge and personal interests. Help them to link what they already know to what they would like to find out.

4. Create a conducive environment that encourages problem-posing and question-asking (p. 281).

In addition to the teachers' skill in the questioning process, student-generated questions in science learning have been strongly advocated in inquiry-based science (White \& Gunstone, 1992). Students' questions are able to reveal much about the quality of their thinking and conceptual understanding (White and Gunstone 1992; Woodward, 1992), their misconceptions (Maskill \& Pedrosa de Jesus 1997) and their interests (Elstgeest, 1985). It has been even been postulated that student questions can provide "critical incidents for teachers, forge critical reflection about the nature of science and the processes of teaching and learning, and generate shifts in their thinking and classroom practice" (Chin, 2002, p. 522). While student questions do lead to critical reflection, the responses that students make may be even more important to the overall goals of the inquiry process. It has been well documented in the literature that classroom talk has traditionally been dominated by teachers with too time devoted to student reasoning (Alexander, 2006). Correspondingly, in studies involving inquiry science, there has been a lot of emphasis on teacher questioning, but there has not been much attention to the analysis of student response patterns.

It is evident an educational reform movement to install inquiry-based pedagogy is well underway in both the US and Lithuania. As Lithuania joined the European Union, national and international professional development opportunities were made available to science teachers. In addition, Western professional development programs were offered in the summers to augment bridging the gap between current educational practices and those needed for the $21^{\text {st }}$ Century. Lithuanian teachers are beginning to be aware of how much students benefit from the engagement of inquiry learning. At the same time, they are cautious; as they feel pressured to spend an exact amount of time 
covering specific content for accountability purposes.

The situation is not all that different in the US, the National Research Council has called for inquiry instruction to promote coherent understanding of science (1996). However, while inquiry-based teaching is at the heart of science education reform, US teachers also feel pressured to cover state content standards and encounter other barriers to full implementation of inquiry teaching (Author \#2 \& Author \#1, 2010).

\subsection{Research questions}

For this reflection we drew on the theoretical constructs grounded in the literature of inquiry learning. The framework that we used to guide the comparisons is based on constructivism, which posits that knowledge is actively constructed by learners through an interpretation of their experiences (von Glasersfeld, 1995) and from negotiated meanings through social interactions (Vygotsky, 1978). The National Research Council's (NRC) Next Generation Science Standards (NGSS) are aligned with these definitions of constructivism and this study follows NGSS definitions of inquiry-based teaching. A primary objective of the research was to document the progress and impact of inquiry-based pedagogy in US (Southern California) and Lithuanian elementary classrooms. As such, the purpose of the research and visits to particular $4^{\text {th }}$ grade classrooms was to obtain qualitative data on the status in each context. This data provides a window into the development of teachers' inquiry-based pedagogy, as well as the effectiveness of questioning in developing a learner's critical thinking skills. Both teachers in the US and in Lithuania are well aware of the critical role that questioning plays in inquiry-based teaching. We wanted to reflect upon whether or not there are similar patterns in both teacher questioning and student responses in teaching inquiry based science in each country. The overarching reflective research questions were:

- To what extent are US and Lithuanian fourth grade teachers employing effective inquiry-based strategies in their classrooms, based on researcher observations?

- What are the similarities and differences between US and Lithuanian teachers in their questioning strategy approaches in inquiry-based pedagogy?

\section{Method}

\subsection{Participant Characteristics}

The fourth grade classrooms chosen for this study represent teachers who had participated in inquiry-based professional development (PD) seminars. In the US, experienced elementary teachers attended a five day summer institute and seven additional Saturday sessions of an Inquiry Learning Institute, as part of a large state-funded grant. Authors \#1 and \#2 were part of the summer institute that introduced inquiry-based learning in math and science. Content sessions, taught by University faculty featured physical, earth and life science and addressed formative assessment, use of student notebooks, adapting traditional curriculum to inquiry-based pedagogy and best practices. These teachers, from two southern California school districts, were evenly distributed between grade levels 4-6 and participation was free and voluntary although, the teachers were recruited from low-performing schools. The format for PD followed a pattern of lectures on subject matter, hands-on inquiry experiences for "teachers as learners", and demonstration of inquiry practices balanced with workshops that constructivist designed and offered teachers opportunities to interact through group work and hands-on experience with science kits. From the total group of 110 teachers participating in the PD, six female teachers volunteered to allow researchers to attend their classrooms and videotape their inquiry-based science lessons. In addition, the teachers participated in a focus group

In Lithuania, ten schools were selected in and around Kaunas and Vilinus Lithuania. Many of the teachers and/or school administrators in these schools had previously participated in targeted inquiry-based, science content, two-week workshop during the summer. These workshops, sponsored by the American Professional Partnership for Lithuanian Education (A.P.P.L.E.), invited American educators (including author \#2) to Lithuania to lead teacher development efforts. The summer workshop centered around what it means to transition learners from students to scientists. Lithuanian teachers explored how to guide students through examining real world problems and the science learning embedded in investigating these authentic issues. The notion that an inquiry-based classroom is one that fosters exploration of ideas, experimentation, creativity, and lots of thinking was taught in English and translated by an interpreter (who was knowledgeable in inquiry pedagogy). The expected outcome for the summer workshop was for each participant to have a repertoire of strategies and activities to create a strong authentic inquiry-based science classroom. In Lithuania, fourteen female elementary teachers and one male teacher volunteered to teach a science lesson and be observed by author \#2 and the Lithuania translator who had also been present for the summer workshop. While the lessons observed in the US and in Lithuania varied greatly in topic, the basic pedagogy was inquiry-based. All teachers who participated in the study were veteran teachers with between 1-14 years of 
experience and the classrooms compared were all fourth grade level. While participant variability was diverse in terms of teaching experience, this diversity provided a broader understanding of the teacher's role in the inquiry process.

\subsection{Data Collection and Analysis}

Data collection took place after participants had completed their respective summer inquiry-based pedagogy training. A focus group was held with US teachers at the conclusion of the Inquiry Learning Institute and in Lithuania, teachers were interviewed separately. Classroom visitation appointments were set up and each classroom visits in both countries was video recorded. In the US, the videotapes were scripted and analyzed. In Lithuania, the videotapes were translated, scripted and analyzed. Highlighted practices and training paradigms most desired by educators and deemed necessary to improve educational practices in each country were noted with particular attention paid to interactions that involved the research questions. To maximize the potential strengths of videotape analysis, the authors used protocols described by Lesh and Lehrer (2000). Videotape analysis went through revision cycles where we reviewed the tapes multiple times through different lenses looking to confirm and disconfirm our assertions. We filtered, selected and organized video vignettes to produce stable and consistent interpretations of the video. The resulting data analyzed using Lincoln and Guba's (1985) method of unitizing and categorizing components. All the coded sections of the data were placed in "provisional categories" using the method of constant comparison. In analyzing the transcripts of the classroom lessons, special attention was given to the questions that teachers asked and corresponding responses of the students.

\subsection{Research Design}

This research employed a qualitative method approach (Creswell, 2009). Triangulation was accomplished through the analysis of different data sources (Classroom observations, interviews with participant teachers, level of participation in inquiry-based pedagogy professional development, and researcher field notes). An essential aspect of qualitative analysis is the search for patterns that unite previously isolated incidents. This search for patterns allowed us to explore similarities and differences between pedagogical approaches in the two countries under comparison. We took a critical reflection approach to analyzing the data.Our critical reflection was a process carefully examining the pedagogical intentions of the teachers and teaching events to link elements of conscious thinking, making meaning, deliberative action, and higher student learning as a cyclical process (Alfaro \& Quezada, 2010).

\section{Results}

\subsection{Coding of Data}

The qualitative analytic process of all of the classroom observations, teacher focus group/interviews, and research field notes initially produced three categories (questioning strategies, teacher's understanding of inquiry, extent students are engaged in critical thinking) for coding the data. Within these categories, two reoccurring themes emerged and were used to organize and interpret the data. These two themes are:

a) Teacher's use of questioning to guide critical thinking.

b) Role of inquiry-based pedagogy in promoting student engagement.

\subsection{Teacher's use of questioning to guide critical thinking.}

Five questioning patterns emerged from the transcripts of the inquiry lessons. (1) scaffolded questions, (3) open-ended or unstructured questions, (3) questions that paraphrased student answers, (4) questions intended to make connections to students' prior knowledge, and, (5) probing questions that required the learner to provide a rationale. What follows are some data examples of the question patterns in actual question/answer vignettes from the US and Lithuanian fourth grade classrooms.

(1) Scaffolded questions: Scaffolding refers to supports that teachers provide to the learner during problem solving in the form of reminders, hints, and encouragement - to ensure successful completion of a task. An important feature of scaffolding, especially in authentic contexts is to keep the task whole (Sheppard, 2005). Instructional scaffolding is a layering process designed to build on prior knowledge / answers. Scaffolding is the support given during the learning process, which is tailored to the needs of the student with the intention of helping the student achieve his/her learning goals (Sawyer, 2006). Scaffolded questions are a progression of questions that a teacher uses to guide a learners thinking, eventually leading to consensus (with the content). Various and numerous scaffolded questions were observed in both US and Lithuanian science lessons. 


\section{US example- Subject Matter: How a compass works}

The teacher has passed around a brown bag with a hidden object in it. The teacher provided clues of the object's identity and students guessed that it was a compass. Now the teacher is guiding students in thinking about the forces that cause the needle of the compass to move. She begins by asking about the direction that a compass provides. It is obvious that the students care and are excited about why a compass points north when you are lost in the woods. She continues:

Teacher (T)-“What forces do you think affect a compass?"

Student (S): I think wind.

T: So, if I blow on it, will the needle move?

S: No?

T: Let me pass a compass down each row so that you can look at them and investigate to decide what forces control a compass.

S. (Blows on face of compass to observe that the needle does not move). Her "no?" turns into "no."

The teacher's scaffolded approach has led students to consider various forces that may or may not cause a compass needle to move.

\section{Lithuanian example-Subject Matter: Mixtures}

The teacher has read a definition of a mixture from a book and provided an example, water + salt equals a mixture. Students have taken out their notebooks to copy the definition. The teachers asks, "Do you understand?" She answers her own question, "Liquid water and another material that will dissolve in that water makes a mixture." The teacher performs a demonstration of pouring water into glasses and then adding various components: salt, washing powder, lemon juice, and oil. After each demonstration, she asks, "Can you see small particles?"; "Are there any hard pieces in it?"; Is it a pure liquid?"

T: What about oil? What can you see?

S: Oil at top, water at bottom,

$\mathrm{T}$ : Then, is it a mixture?

S: No

The teacher's scaffolded questions have led the student to a correct application of the concept of "mixture".

(2) Open ended or unstructured: An open-ended question is designed to encourage a full, meaningful answer using the student's own knowledge and/or feelings. It is the opposite of a closed-ended question, which encourages a short or single-word answer. Open-ended questions are essential in science inquiry because it moves the learner toward meta-cognition. Asking open-ended, or divergent questions such as "what are you doing?"; "tell me about what you're thinking?" and "What do you think would happen if . . ??" encourage the learner to dissect their thinking or actions and provide rationales.

\section{US example: Subject matter: Magnets}

$\mathrm{T}$ : What does it mean when I say, "I am going to investigate something”?

S-Trying to find information about it.

$\mathrm{T}$ : What is something that you are wondering about magnets?

S. Can they pick up a car?

S. Are bigger magnets stronger?

T: We are going to look at some of your questions to see if they are something we can actually test.

The teacher has passed out magnets to table groups of students. Each table is then given a plastic bag with a variety of materials in it: paper clips, nail, wooden dowel, plastic beads, coins, another magnet, cardboard square, rubber band, piece of jewelry, etc. After a few minutes of investigation, the teacher asks:

$\mathrm{T}$ : What are some things you noticed (about the properties of magnets)?

$\mathrm{S}$ : The magnet does not stick to the piece of wood.

S. The magnet can stick to two things at one time. 
S: The magnet can pick up the paper clip at a certain distance.

With no single right or wrong answer to the teacher's open-ended questions, the learners share insights and ideas as they build knowledge of the properties of magnets.

\section{Lithuanian Example: Subject Matter: Magnets}

The class began with the teacher putting 4 pictures on the black board: braids, train, compass and a family. Each picture had circles beneath with some lines drawn through. Under braids, 5 circles, last 2 were marked out and first three, students filled in with "kas." Picture of the train: 7 circles, last two marked through spells: traukia. Picture of the compass: 4 circles, middle two marked through and students put word "kaip". Last picture: family had 8 circles and all but first letter and last two letters were marked through:

Word that appeared from the puzzle: magnetas (magnets)

T- Stresses purpose of lesson: What attracts like magnets? What is a magnet and what properties does it have?

T: Teacher holds up a horseshoe with all sorts of things attached and says, "I have a problem. I was mending a bag and lost a needle. I was here in the classroom and the cleaning lady may hurt herself if I do not find the needle. I was looking but could not find it. Maybe you could help me. Volunteers?? (To try and find the needle?)

S: I found a tack.

T: Teacher laughs and says, "good, but not the needle". Ah, a student finds it.

T- What helped us?

$\mathrm{S}$ : The magnet, it has the power to attract.

T- This needle is dirty since it was under the table. I'll wash it. (She puts in into a glass of water.) "Now, how do I get it back? Does magnetic field work through water?"

The teacher's seemingly innocent open-ended questions are designed to encourage student thinking. She has built a scenario to provide a context for how a magnet might be used in everyday life. At the end of the lesson students have thought of a multitude of purposes for magnets: closure clasps in purses, stick things to the refrigerator, to find lost items (that contain iron), jewelry, games, etc.

(3)Paraphrasing student response into a question: The essence of paraphrasing is verification or understanding the thought. Paraphrasing is also a way of showing active and effective listening to the student demonstrating that the teacher understands and cares about what is being said. Paraphrasing allows teachers to re-articulate, re-order, or clarify a learner's thinking by using alternative vocabulary, restructuring ideas, or filling in the blanks. The paraphrased question also allows the teacher to broaden or bring more focus to what was just said.

\section{US Example- Subject matter: magnets}

T: So, you are saying when you moved it (the magnet) around, all the metal stuck to it but it was hard to pull off? (teacher reiterates student thoughts for clarification)

$\mathrm{S}$ : Yes, if I put the magnet with the metal, it (the magnet) sticks with the nail but the metal is not like the magnet.

T: I am going to use the word "pull" for "sticks", would that work?

The teacher's paraphrasing questions are guiding the learner to consider magnetism as a force that has a "pull".

No examples of paraphrasing question strategies in Lithuania (may be a result of the translation process).

(4.) Questions that activate prior knowledge: Activating student prior knowledge or making connections between what learner already knows and new material, has been found to be critical in learning new information (Resnick, 1983).

US Example: Subject matter: How a compass works

Teacher is playing 21 questions with students: What am I? A compass.

T: Clue: It helps you when you get lost.

S: (A chorus of Ohhs and Awwws from children). Shouts of "a compass".

T: What made you think of a compass?

S: Once when I was watching something on T.V., it said, "compasses are not very high tech, but they have a needle that always points north (to help you find your way). 
This line of questioning informs the teachers to where children are getting their prior information on a topic and also reveals misconceptions that the teacher may need to address.

\section{Lithuanian example-Subject Matter: Antarctica}

The lesson opens with an adult dressed as a hunter entering the room and telling the teacher that she had meet an interesting bird, a penguin, that lives on a cold continent.

T: What do you know about Antarctica?

S: Penguins

S: Frozen ice

T: Is there anything else?

S: Surrounded by sea,

T: Any land or soil?

S: No, just ice and the caca of animals, rocks.

T: O.K. Let's visit the penguins. What do we need? Air balloon? Plane? Imagine you are flying (teacher throws feathers into the air). Make the feathers fly. (Children get up from their desks and blow on the feathers to keep them in the air.)

T: we have landed. Let's sit down. Was the journey long?

After enacting this scenario, the teacher has a good feel for what her learner do and do not know about the continent of Antarctica. She uses this information to build her next lesson.

(5) Probing Questions: Asking students probing questions allows a teacher to dig deeper into the rationale behind the answer that was given. These types of questions go to the heart of inquiry, asking, "how do we know?; what is the evidence?; What can we do to find out? Probing questions help students figure out how to start making evidence based observations. Broadly focused questions allow students to decide what they should look for on their own, while narrowly focused questions help students recognize details that they might have missed. Probing questions may include, "What do you think will happen if you try . . . or What do you think you should do next? (Author \#2 \& Fontichiaro, 2009).

US example- Subject matter: Magnetism

$\mathrm{T}$ : What did you notice?

$\mathrm{S}$ : The magnet is like a vacuum cleaner.

T: Can you be more specific? Tell me how you think it is like a vacuum cleaner.

S: The magnet is sucking up metal stuff.

T: What is another word we can use for "sucking it up"? Because when we are sucking up milk with a straw it goes into my body; it's gone, so are all your little pieces gone?

S: No, they are staying there.

T: So what's another word?

S: Sticks, the little pieces stick to the magnet.

The teacher's probing into the meaning of the student's action verb "sucking" causes the student to rethink her response and clarify how a magnet attracts other objects.

\section{Lithuanian example- Subject matter: Gravity}

Teacher is conducting a classroom discussion around the topic of gravity.

T:Are raindrops attracted by Earth?

S: Yes

T: Why doesn't a ship go to bottom of sea if Earth attracts it?

S: Because of engines.

$\mathrm{S}$ : Engines are stronger than power of earth.

T: Why aren't birds and planes attracted by Earth? (no student responses) 
T: Does Earth attract everything?

S: Yes

T: Like a magnet?

T: No.

These types of probing questions guide students to derive scientific concepts. The progressive questioning pushed students beyond factual recall to elaborate on and explain their thinking. Moyer and Milewicz (2002) found that probing questions helped the teacher to better focus on students' thinking.

\subsection{The role of inquiry-based pedagogy in promoting student engagement}

In the summer workshops, teachers learned to shift their pedagogy from teacher-centered to student-centered as they enacted inquiry-based pedagogy. Of the twenty-one classes visited, 100\% demonstrated implementation of inquiry strategies in one form or another. In a focus group, US teachers were asked, "In what ways do you think that this inquiry learning will facilitate your teaching? Do you think that it will have an impact?"

Teacher \#1: Yes, because I think that starting off with a problem posing is doing some things with the motivation for students. When they are engaged with their own questions, they are going to further and deeper than they have gone before. Students will go in different directions that not only the teacher has not thought of but also the textbook might not spend enough time on. The teacher has to be more prepared to be able to lead students at that point rather than just presenting the material and then just getting back rote answers.

Teacher \#2: Inquiry allows students to create their own paths and go with their passion and where the content may take them.

Teacher \#1: Exactly. And the other part is the time that is going to be spent using those skills inquiring about ideas is much more that you could ever get in worksheets or the "right answer."

The teacher perception of inquiry-based pedagogy is that it provides learners with authenticity and relevancy. One teacher in the US said, "I questioned intentionally. I tried to anticipate student responses to questions and wrote these anticipations into my plans." This teacher strategically planned for high student engagement. Another US teacher indicated that she intended a planned progression from posing questions to fostering student responses, and finally to having students discriminate between questions that were testable and those that were not. In this case, inquiry pedagogy promotes student engagement and thinking through the making of judgments. Students must analyze the merits of the question and decide if it can be tested. Similarly, a Lithuanian teacher indicated that she was able to build her subsequent questions (on the fly) from student responses. She indicated that not only did inquiry pedagogy promote greater student engagement, but the teacher is also actively engaged trying to think of questions based on the answers given in class. Another teacher noted, "Student engagement was HIGH! They were creating their own experiments and different modes of communication were used, not just the textbook. Kids who don't normally pay attention were able to synthesize and apply their knowledge." This teacher found that collaborative work by students improved conjecture making, and the quality of discourse in student talk. The teachers role became one of facilitation through the discourse.

Some culturally based pedagogical traditions were also observed in the inquiry practices of teachers from the two nations. For example, in Lithuania "exercise moments" were included in each observed science lesson. The lesson on Antarctica had students up out of their seats to blow on feathers and the lesson on magnets had students up searching for a needle. Other Lithuanian lessons included songs with hand motions or scavenger hunts for particular science objects. This inclusion of purposeful exercise (or small relaxation moments) was not observed in US classrooms. Rather US teachers were on a pacing guide and pressured to cover a certain amount of content by a specific deadline. With strict standardized testing in place in the US and teacher accountability for student achievement on the rise, US teachers were concerned with the amount of class time that inquiry pedagogy required. As one US teacher noted, "I am overwhelmed by all of the content we are expected to cover in the fourth grade."

Another cultural difference that was observed was that in Lithuania, hands-on activities tended to conserve resources, while still being engaging. The teachers employed a type of voyeuristic inquiry: with students looking at the experiment, grappling with the questions poised by the investigation, but not actively doing it. For example, the mixture investigation was actually a demonstration by the teacher (using only one set of materials instead of a set for each group of students). Yet, each "mixture" was passed from one student to the next to allow for close-up observation. In the Lithuanian magnet discussion, only one horse-shoe shaped magnet was displayed by the teacher, however students generated most of the characteristics of magnets from the teacher's storied presentation (e.g. lost 
needle $=$ magnets attract items containing iron; the magnetic force applies through water, etc.). On the other hand, in the US, sets of magnets and materials were provided to each group of four or five students for hands-on manipulation and the same generation of characteristics of magnets.

\section{Discussion}

\subsection{Bi-national comparison of inquiry-based science practices in US and Lithuanian classrooms}

Inquiry-based practices are being implemented in elementary science classrooms in both the US and Lithuania. The teachers' understanding of inquiry pedagogy and their ability to actively engage learners in critical thinking about science concepts, according to these researchers' observations, was comparable in both nations. In implementing inquiry pedagogy, both Lithuanian and US teachers had a good questioning skills for helping learners make connections between what they already know and the new material being presented. Teachers in both countries allowed students to grapple with answers to the inquiry, not providing answers rather having the learners walk the fine line between frustration and engagement. In both national contexts, the inclusion of student prior knowledge into the discourse provided validation for learners and a window of insight for the teacher as to where learners were obtaining their prior knowledge. The teachers used demonstration or hands-on materials so that students can develop their observational skills and learn to make evidence-based claims. We observed in both countries that the more familiar the activity, materials, or context of the investigation, the easier it was for students to apply the content learned through inquiry. No matter the geographical location of the classroom, in the successful inquiry-based classroom, the teacher's guidance was the key element to learner attainment of scientific concepts. These teachers avoided directly telling students answers to questions, they encouraged rather than discouraged student thinking outside the box, and they responded to students without praising or criticizing, which encouraged students to think for themselves and not look to the teacher for validation.

In comparing the questioning patterns that teachers used for science inquiry, we noticed that the essential outcomes of inquiry teaching (NRC, 2000) and promotion of learner's critical thinking were observed in classrooms located in both nations. Moreover, we found that both teachers' questions and students' responses followed similar patterns in each nation. Where differences did occur, those differences tended to be related to the lesson's content, institutional structure and guidelines (e.g. schedules, pacing guides, lack of resources), or the effects of translation and not to the utilization of inquiry-oriented protocols.

However, sometimes a teacher's perception of their inquiry strategy did not match our observation of said strategy. For example there was a difference between a teacher's perception of inquiry and that teacher practice in one US classroom:

Teacher perception of open inquiry: In preparing for an inquiry into erosion controls for landforms, the teacher says to class, "Ask ANY question." Meaning that students could generate a testable inquiry question for the investigation. However, the teacher then proceeded to provide students with a handout of prepared testable questions and tells the students, "choose one of these questions." The teacher explains that she must maintain some control over the questions that will be investigated so that she will have the proper materials for students to conduct the experiment. So, in theory, the teacher wanted students to devise a testable inquiry question, but in reality, students were simply given a choice of testable inquiry questions.

Finally, there were certain surprises that arose during our time with teachers in each nation.

- Teachers in the US, especially, felt overwhelmed by all of the strategies they are expected to use in their classrooms. Creating deep inquiry-based questions to promote higher-level student responses, while seen as a positive classroom protocol by teachers, also became burdensome when added to other reform measures they were asked to do. Therefore, it was important for these teachers to draw connections between methods they were already using and any "new" inquiry techniques so that implementation was not a burden.

- In both nations the need for materials to teach inquiry science is evident. However, in Lithuania, teachers were much more willing to use materials at hand to create good environments for teaching inquiry. It was also noted in Lithuania that some of the equipment was approximately 40 years old. In the US, teachers were less likely to implement inquiry strategies if they did not have adequate materials to conduct investigations.

- In both nations the support of administrators was key in providing teachers the flexibility and confidence to take the risks necessary to make authentic change in their classrooms.

- In spite of the inquiry training, teachers in both nations used some non-effective questioning strategies as well. Examples of these were questions that were framed as "Do you understand?" or "Do you have any questions?" These 
non-effective question frames did not produce high-level student responses, and in many instances, produced no student responses at all.

\subsection{Limitations of study}

Because of the limited scope of this study in examining 6 classrooms in the US and 15 classrooms in Lithuania, generalizations cannot be made, only reflections.

\subsection{Conclusion}

The implications of the present findings are clearly relevant to the discourse for the successful implementation of science education reforms that advocate inquiry-based pedagogy (e.g. Next Generation of Science Standards (NGSS) in the US; Lithuania's National Education Strategy 2003-2012). There is an international awareness of the need to teach science in ways that encourage critical and creative thinking, skills that are universally needed by the world's workforce in the $21^{\text {st }}$ century. However, even though schools around the world have received the call to endorse inquiry-based science methodologies, there still seems to be a gap in implementation by classroom teachers. In the US, teachers face challenges in implementing this pedagogy in their classrooms (NRC, 1996). And, in Europe, an examination of classroom practice shows that in the majority of European countries, these methods are only being implemented by relatively few teachers (Rocard, M., Csermely, P., Jorde, D., Lenzen, D., Henriksson, H. W., \& Hemmo, V., 2007).

\section{Acknowledgements}

We wish to acknowledge and thank teachers in the US and in Lithuania who graciously allowed us to observe them in teaching inquiry science lessons to their students.

\section{References}

Abd-El-Khalick, F., Boujaoude, S., Duschl, R., Lederman, N., Mamlok-Naaman, R., Hofstein, A., Niaz, M., Treagust, D., \& Tuan, H-L. (2004). Inquiry in science education: international perspectives. Science Education, 88, 397-419. http://dx.doi.org/10.1002/sce.10118

Alexander, R. (2010). Speaking but not listening? Accountable talk in an unaccountable context Speaking but not listening?.Literacy, 44(3), 103-111. http://dx.doi.org/10.1111/j.1741-4369.2010.00562.x

http://www.tandfonline.com/doi/abs/10.1080/02671520500445425\#.UdBKMRa-NfQ

Alfaro, C. \& Quezada, R. (2010). International teacher professional development: Teacher reflections of authentic teaching and learning experiences. In Teaching Education (Quezada) Internationalization of teacher education: Creating globally competent teachers and teacher educators for the $21^{\text {st }}$ century. Great Britain: Routledge. http://dx.doi.org/10.1080/10476210903466943

Biddulph, F., Symington, D. \& Osborne, R. (1986). The place of children's questions in primary science education, Research in Science and Technological Education, 4 (1), pp. 77-88. http://dx.doi.org/10.1080/0263514860040108

Author \#2 \& Author \#1. (2010). Impact of professional development on teacher practice: Uncovering connections. Teaching and Teacher Education, 26(3), 599-607. http://dx.doi.org/10.1016/j.tate.2009.09.006

Author \#2 \& Fontichiaro, K. (2009).Story starters and science notebooking: Developing children's thinking through literacy and inquiry. Westport, Conn: Teacher Ideas Press.

Butrymowicz, S. (2012). Why are other countries doing better in science that the U.S.? The Hechinger Report.

Chang, C.Y. \& Mao, S. L. (1999). Comparison of Taiwan science students' outcomes with inquiry-group versus traditional instruction. Journal of Educational Research, 92 (6), 340-346. http://dx.doi.org/10.1080/00220679909597617

Chin, C. (2002). Student-generated questions: a meaningful aspect of learning in science. International Journal of Science Education.24 (5), 521-549. http://dx.doi.org/10.1080/09500690110095249

Chin, C. (2004). Questioning students in ways that encourage thinking. Teaching Science. 50 (4), 16-21.

Chin, C. \& Kayalvizhi, G. (2002). Posing questions for open investigations: What questions do pupils ask? Research in Science and Technological Education, 20(2), 269-287. http://dx.doi.org/10.1080/0263514022000030499

Creswell, J. (2009). Research design: Qualitative, quantitative, and mixed methods approaches (3rd ed.). Thousand Oaks, CA: Sage Publications. 
Crockett, C. (2004). What do kids know and misunderstand about science? Educational Leadership, 61, 34-37.

Crow, M. \& Stanford, P. (2010). Questioning for quality. The Delta Kappa Gamma Bulletin, 36-44.

Elstgeest, J. (1985). The right question at the right time. In W. Harlen (ed.) Primary Science: Taking the Plunge (London: Heinemann), pp. 36-46.

Exforsys, Inc. How to paraphrase questions. Retrieved on February 8, 2013 from http://www.exforsys.com/career-center/questioning-skills/how-to-paraphrase-questions.html

Geier, R., Blumenfeld, P., Marx, R., Krajcik, J., Fishman, B., \& Soloway, E. (2008). Standardized test outcomes for students engaged in inquiry based science curriculum in the context of urban reform. Journal of Research in Science Teaching.45(8), 922-939. http://dx.doi.org/10.1002/tea.20248

Hanushek, E., Peterson, P. \& Woessmann, L. (2012). Acheivement Growth: International and U.S. State Trends in Student Performance.

Inoue, N. \& Author (2011). You asked open-ended questions, and now what?: Understanding the nature of stumbling blocks in mathematical inquiry lessons. Mathematics Educator, 20, 10-23.

Janiuk, R.M. (2003). Education of science teachers - some remarks from the Polish perspective. Journal of Baltic Science Education, 2(4), 38-48.

Jonane, L. (2005). Finding possibilities to improve science education in high school and gymnasium. Journal of Baltic Science Education, 1(7), 63-69.

Jucevieiene, P. (2005). The evolution of national education and educational thought in Lithuania. European Education, 37 (3), 8-19.

Keys, C. W. (1998) A study of grade six students generating questions and plans for open-ended science investigations. Research in Science Education, 28, 301-316. http://dx.doi.org/10.1007/BF02461565

Lesh, R. \& Lehrer, R. (2000). Iterative refinement cycles for videotape analysis of conceptual change. In A. E. Kelly, \& R. A. Lesh (Eds.). Handbook of research design in mathematics and science education.Mehwah. NJ: Lawrence Erlbaum Associates.

Lincoln, Y., \& Guba, E. (1985). Naturalistic inquiry. New York: Sage.

Lin, M. C., Davis, E. A. \& Bell, P. L. (Eds.), (2004). Internet environments for science education. Mahwah, NJ: Lawrence Erlbaum Associates.

Linn, M. C, Clark, D., \& Slotta, J. D. (2003). WISE Design for Knowledge Integration. Science Education, 87,517-538. Michael, R. (2002). What is Inquiry? Retrieved 17/02/2012, from http://dx.doi.org/10.1002/sce.10086

Maskill, R. \& Pedrosa de Jesus, H. (1997). Pupils' questions, alternative frameworks and the design of science teaching. International Journal of Science Education, 19, 781-799. http://dx.doi.org/10.1080/0950069970190704

Mercia, K. (2007). Science for the 21 st century: Teaching for scientific literacy in the primary classroom. Teaching Science. 3 (2), 16-19.

National Research Council (NRC) (1996). National science education standards. Washington, DC: National Academy Press.

O’Loughlin, M. (1992). Rethinking Science Education: Beyond Piagetian Constructivism toward a Sociocultural Model of Teaching and Learning. Journal of Research in Science Teaching, 8 (29), 791-320.http://onlinelibrary.wiley.com/doi/10.1002/tea.3660290805/abstract

Organisation for Economic Co-operation and Development (OECD). Programme for International Student Assessment (PISA). (2006). Assessing scientific, reading and mathematical literacy: A framework for PISA $200 b$.

Resnick, L.B. (1983). Mathematics and science learning: A new conception. Science, 220, 477-478. http://dx.doi.org/10.1126/science.220.4596.477

Rocard, M., Csermely, P., Jorde, D., Lenzen, D., Henriksson, H. W., Hemmo, V. (2007). Science Education Now: A New Pedagogy for the Future of Europe. European Commission Directorate General for Research Information and Communication Unit. Retrieved $2 / 15 / 2013$, from 
http://ec.europa.eu/research/science-society/document_library/pdf_06/report-rocard-on-science-education_en.pd $\mathrm{f}$

Roth, W. M. \& Roychoudhury, A. (1993). The development of science process skills in authentic contexts Journal of Research in Science Teaching, 30 (2), pp. 127-152. http://dx.doi.org/10.1002/tea.3660300203

Sawyer, R. Keith. (2006). The Cambridge Handbook of the Learning Sciences. New York: Cambridge University Press.

Schmidt W. H. \& McKnight, C. C. (1995). Surveying educational opportunity in mathematics and science: An international perspective. Educational Evaluation and Policy Analysis, 17(3), 337-353.

Selley, N., Wodehouse, S., Parnum, C., Mathews, N., Michie, M., Law, G., Lahr, H., Edmonds-Seal, L. \& Clarke, C. (1992). Children investigating their own questions, PrimaryScience Review, 21, pp. 3-4.

Shepard, L. A. (2005). Linking Formative Assessment to Scaffolding. Educational Leadership, 63(3), 66-70.

Valverde, G. A. \& Schmidt, W. H. (2000) Greater expectations: learning from other nations in the quest for 'world-class standards' in US school mathematics and science. Journal of Curriculum Studies, 32(5), 651-687. http://dx.doi.org/10.1080/00220270050116932

Von Glasersfeld, E. (1995) Radical constructivism: A way of knowing and learning. New York, NY: Routledge. http://dx.doi.org/10.4324/9780203454220

Vygotsky, L.S. (1978) Mind in society: The development of higher psychological processes. Cambridge, MA: Harvard University Press.

Wallace C. S., Kang, N. H. (2004). An investigation of experienced secondary science teachers' beliefs about inquiry: An examination of competing belief sets. Journal of Research in Science Teaching, 41(9), 936-960 in S. Buczynski\& C. Hansen, C.B. (2010). Impact of professional development on teacher practice: Uncovering connections. Teaching and Teacher Education,26(3), 599-607.

Watts, M. \& Alsop, S. (1995) Questioning and conceptual understanding: the quality of pupils'questions in science, School Science Review, 76 (277), pp. 91-95.

Watts, M., Gould, G. \& Alsop, S. (1997) Questions of understanding: categorizing pupils'questions in science, School Science Review, 79 (286), pp. 57-63.

Wilson, C., Taylor, J., Kowalski, S., \& Carlson, J. (2010). The relative effects of inquiry-based and commonplace science teaching on students' knowledge, reasoning and argumentation: A randomized control trial. Journal of Research in Science Teaching.

White, R. T. \& Gunstone, R. F. (1992). Probing understanding. London: Falmer Press.

Woodward, C. (1992). Raising and answering questions in primary science: some considerations. Evaluation and Research in Education, 6, 145-153. http://dx.doi.org/10.1080/09500799209533324 